\title{
Restorative Rhythms: drumming as healing
}

By: Justin Harmon and Alexandra Arpajian

Harmon, J., \& Arpajian, A. (2020). Restorative Rhythms: Drumming as healing. World Leisure Journal, 62(1), 67-80. doi: 10.1080/16078055.2019.1611629.

This is an Accepted Manuscript of an article published by Taylor \& Francis in World Leisure Journal on 30 April 2019, available online: http://www.tandfonline.com/10.1080/16078055.2019.1611629.

$* * *$ (C) 2019 World Leisure Organization. Reprinted with permission. No further reproduction is authorized without written permission from Taylor \& Francis. This version of the document is not the version of record. ***

Abstract:

Thirty people who were either in treatment, or in remission, from cancer and their caregivers participated in a therapeutic drumming clinic called Restorative Rhythms. As music has been proposed as a significant way to reduce stress and stimulate feelings of happiness and empowerment, it is therefore a valuable tool for coping with illnesses like cancer. Because people who are diagnosed with cancer often have trouble expressing their emotions, music can be used as an accessible channel for this necessary release. In addition to the inability to express internalized emotions derivative of the diagnosis or due to the requirements of the treatment regimen, patients often lose their sense of agency; creative expression like therapeutic drumming can help them regain their autonomy. This social, creative environment became a means to express the emotions participants were otherwise having trouble expressing, as well as a positive outlet for coming to terms with their "new normal" through music.

Keywords: Music | cancer | posttraumatic growth | leisure

Article:

When you get the [cancer] diagnosis you don't know anything. You're standing at the door of the unknown with your hand on the knob and that's it. Someone has just pushed an envelope under the door and you've opened it: "Your time is up." You're getting ready to turn the knob and go in this dark hallway into the unknown. The diagnosis was a reminder that I wasn't living to the level that I wanted to. What have I been saying "no" to that I should have been saying "yes" to [all along]? I decided I was going to say "yes" to everything after that. "You're scared of getting up in front of people and playing a musical instrument?" You've had cancer! Go do everything! My year of "yes" has just turned into a lifetime of saying "yes." - From interview with Buffy (56, breast cancer)

\section{Introduction}


Much research has been conducted on the importance of music in establishing and maintaining one's quality of life (QOL). Music, or rather rhythm, syncopation, and sound, is an integral and ever-present component of the human experience. During the earliest moments of our development, we are exposed to an "intrauterine symphony" composed of the mother's heartbeat, her voice, and the noises of the surrounding environment for which we come in to contact with on a daily basis during our period of gestation (DeNora, 2000). After we are born, we continue to be exposed to the sounds of our environment, and these sounds are essential to our growth and understanding of how to interact with our surroundings (Schlaug, Norton, Overy, $\&$ Winner, 2005). One of the primary collections of sounds that come into play for our personal development is that of music (Hargreaves \& North, 1999).

Merriam (1964) stated that there is likely no other human cultural activity which is as pervasive as music, and that music has the potential to reach into the depths of the human mind and soul to shape and affect human behaviour. Cross (2001) stressed the important social components of music in creating the grounds for interaction and construction of meaning, both internally and externally. DeNora (1995) concurred, having stated that music is a cultural resource that individuals draw on for their own construction of self, which includes the emotional, memory, and biographical work they do to learn about themselves, their environment, and their social relationships - personal aspects that are imperative to attend to after traumatic experiences like cancer.

It is the discovery of the self and the goal of recovery from cancer through music that is the focus of this manuscript. Schäfer and Sedlmeier (2009) claimed that the most important reason that people like the music they do is that it allows them to express their identity and values, and this creates the opportunity to share these affiliations with likeminded others. Each experience of cancer is unique to the individual. There are, however, often shared elements of the diagnosis, treatment regimen, reactions to medication and treatment, and/or the residual psychological, physiological, and socioemotional components of the total experience that may become anchors for establishing both a mutual understanding and a coping resource amongst survivors of cancer.

Thirty people who were either in treatment, or in remission, from cancer and their caregivers participated in a therapeutic drumming clinic called Restorative Rhythms. Drumming is an internationally dispersed form of music making, which draws on creativity and rhythm to communicate, express culture - and to heal, whether it be for hardship, death, or illness (Akombo, 2013; Fernandez, 2006; Joon, 2001; Nzewi, Anyahuru, \& Ohiaraumunna, 2001; Stephens, 2014). The social, creative environment became a means to express the emotions they were otherwise having trouble expressing, as well as a positive outlet for coming to terms with their "new normal" through music. Thus, the purpose of this manuscript was to demonstrate the value and potential of a non-traditional mode of therapeutic music making and support through leisure for those whose lives have been affected by cancer. What this study sought to address was, how, if at all, does participation in a therapeutic drumming group affect one's ability to address emotions brought on by a cancer diagnosis and treatment?

\section{Literature review}


The thought of making music with different people was so enjoyable. We've all had different upbringings, but we've all had similar experiences. It reminded me of the oneness of life. People who have been diagnosed with cancer all want to live a healthy life. You have this disease in common and it allows you to remove all the barriers, like racism, sexism, homophobia, financial and social background, mood, everyone comes together. It's a wonderful thing. - From interview with Betty (56, breast cancer)

As will be displayed, music has a unique ability to help one connect to a range of emotions and aspects of personal identity. For those affected by cancer, music consumption and production in comfortable settings with people who have had similar illness experiences can be a cathartic tool in the recovery process. As cancer is a traumatic, life-changing event, creative leisure outlets like hand drumming can help survivors of cancer transcend the illness to find growth post-diagnosis of cancer.

\section{Music and $Q O L$}

Ruud (1997a) stated that listening to and talking about music is not so much a reflection of our identity, but more a way of performing it. He went on to say that music could be thought of as an object we act towards in order to clarify our place within the social and cultural constructs of our lives. Ruud (1997b) further elaborated that music is a source of personal authenticity which helps us perceive and give meaning to the world. It is through our development of specific music tastes that we enter into a dialogue with others and society at large. Establishment of our musical preferences aids us in showcasing our spiritual, emotional, and social characteristics (Rentfrow, McDonald, \& Oldmeadow, 2009). The acknowledgement of these preferences can be valuable to making friendships through music association as well as serve as a form of self-therapy that increases positive mood and produces a sense of well-being about life (Saarikallio \& Erkkilä, 2007). Further, music possesses the potential to be a surrogate for human support because of its inherent qualities that attend to issues of identity and meaning making (Laiho, 2004). DeNora (2000) described music as a "powerful medium of social order" (p. 163) which possesses the potential to help us relax, find comfort and inspiration, or simply to make one feel better (Laiho, 2004) when they are facing life hardships like a cancer diagnosis.

\section{Therapeutic aspects of music}

Music therapy

Music therapy is the "professionally informed use of music for people in need of psychosocial assistance and those seeking to experience self-awareness through alternative methods" (Rykov, 2008, p. 199), and refers explicitly to board certified or licenced music therapists. While neither of the authors of this study are board certified or licenced music therapists, the important work of music therapists warrants acknowledgement to illustrate the positive effects of their expertise, intervention techniques, and findings to further demonstrate the potential of music as a therapeutic resource. Hart (2009) stressed the importance of the music therapy instructor, especially for participants without a music-making background, when it comes to eliciting the difficult to express emotions that often accompany trauma and serious illness. Music therapists are also especially adept at helping clients slowly integrate into a music therapy session 
involving receptive, recreative, improvisational, and compositional music experiences, lessening issues of stress and anxiety that not only coincide with their illness, but also that come from involvement in an unfamiliar setting, like a creative music making class (Kenyon, 2007). Music therapists are trained to enhance the positive impacts of participation in their interventions, including paying attention to individual needs and group dynamics (Rykov, 2008).

Music as a therapeutic intervention

Numerous fields of study have used music and drumming as an intervention, including occupational therapy (cf. Plastow et al., 2018); recreational therapy (cf. Petterson \& Loy, 2008); and social work (cf. Maschi, MacMillan, \& Viola, 2012). The Restorative Rhythms (RR) programme uses music to contribute to the holistic care environment for people afflicted by cancer (Daykin, Bunt, \& McClean, 2006), thus embracing its therapeutic potential (Deraney et al., 2017; Dickerson, Robichaud, Teruya, Nagaran, \& Hser, 2012; MacMillan, Maschi, \& Tseng, 2012). Music is proposed to reduce stress and stimulate feelings of happiness and empowerment (Weinberg \& Joseph, 2017), and these were vital elements of the RR programme. Because people who are diagnosed with serious and chronic illnesses like cancer have trouble expressing their emotions, music is recognized as an accessible channel for release and catharsis (Hart, 2009). In addition to the inability to express internalized emotions derivative of the diagnosis, and due to the strict requirements of the treatment regimen, patients often lose their sense of agency; creative expression like therapeutic drumming can help them regain their autonomy (Pothoulaki, MacDonald, \& Flowers, 2012).

Even without a background in playing music, people with cancer can still find great potential for personal transformation (Pothoulaki, MacDonald, \& Flowers, 2005; Ragg, Soulliere, \& Turner, 2019). Not only can active participation in therapeutic music making classes attend to issues of socioemotional well-being, but there have also been studies suggesting that it can attend to the transcendental qualities of humanity like personal spirituality (McClean, Bunt, \& Daykin, 2012). Evidence indicates that the holistic QOL benefits can also positively impact the physical aspects of health including immune system functioning (Kruse, 2003), thus suggesting that music consumption and production are an imperative aspect of life course development (Harmon \& Adams, 2018).

\section{Non-traditional support}

Much of the research on support groups for those diagnosed with cancer has been linked to positive outcomes, including the development of coping mechanisms and improvement in constructive socialization skills which allow the participant to attend to their internalized, often negative, feelings which are resultant of cancer diagnosis and treatment (Docherty, 2004). And while those who have adequate formal (friends and family) and informal social support (through participation in community offerings) have longer survival rates and lower levels of anxiety and depression (Yildirim \& Kocabiyik, 2010), some find support groups to be overwhelming, adding further stress to the difficulties inherent in cancer diagnosis and treatment. At times, patients may find participation in structured support groups that focus on the illness to be depressing, thus being counterproductive to the healing process (Winefield, Coventry, Lewis, \& Harvey, 2003). Therefore, alternative forms of support that focus on QOL through leisure activities (Öster, 
Aström, Lindh, \& Magnusson, 2009; Parry, 2007) like music making have the added benefit of taking the emphasis off of the illness and medicalized treatment and putting it on the enjoyment of personal creativity - from illness to wellness (Daykin et al., 2006; McClean et al., 2012).

\section{Posttraumatic growth}

Kleiber, Hutchinson, and Williams (2002) developed four functions of leisure in its ability to be used as a coping mechanism. They are: leisure to buffer the impact of negative life events by distraction; to generate optimism; to facilitate reconstruction of one's life story; and to serve as a vehicle for personal transformation. To this latter effect, leisure, in this instance therapeutic drumming, then becomes an essential tool in posttraumatic growth (PTG) post-diagnosis of cancer. PTG has been characterized as a "stronger sense of self and values, increased psychological maturity and empathy, improved personal relationships [and] a greater sense of purpose" after a tragic or traumatic incident (Arpawong, Oland, Milam, Ruccione, \& Meeske, 2013, p. 2235). PTG allows people to attend to the process of "cognitive rebuilding," or the experience of improvement after tragedy (Tedeschi \& Calhoun, 2004). Oftentimes PTG is initiated by a diverse social support system (Glover \& Parry, 2009). PTG is not a direct result of the trauma, however. Instead, it is incumbent of the affected to struggle and overcome their hardships, thus leading to the cognitive rebuilding process (Scrignaro, Barni, \& Magrin, 2011). This often leads to a sense of "psychological ownership" of the traumatic experience through an "epiphany" or sensation of accomplishment of the survivor of cancer (Karnilowicz, 2011). As will be evident, the creative, active participation in the Restorative Rhythms therapeutic drumming clinic was a significant resource for those to transcend their illness experience as participants sought to live a healthy and happy life post-diagnosis of cancer.

\section{Methods}

\section{Background of study}

Restorative Rhythms (RR) is composed of four one-hour therapeutic drumming sessions over the course of a four-week programme. There have been three sessions to date with ten participants per session (who participated in all four classes during their respective session). Twenty-three of the participants had cancer at the time of the programme or were in remission from cancer. The majority of the other participants were primary caregivers for their loved ones. The age range for RR drummers was between 38 and 72, and 25 of the 30 drummers were female. Participants were recruited primarily through a local nonprofit arts-based cancer support group, the Hirsch Wellness Network, or the local cancer centre, the Cone Health Cancer Center. Participation was free and there was no expectation to participate in the research component of the programme. The purpose of the RR programme was to provide a creative leisure outlet and experience for those affected by cancer, with the hopes that participants would find some personal healing or catharsis through their involvement. All drumming sessions were audio recorded with the permission of participants in a practice called "conversation netting" (Harmon \& Dunlap, 2018) to be discussed below.

Background on authors/facilitators 
The first author has worked with people diagnosed with cancer since 2014, mostly with naturebased interventions (i.e. hiking), to help survivors cope with symptoms of illness and treatment, to acclimate to life after cancer, and to help instil healthy physical and psychological habits. He frequently works with a local arts-based cancer support organization to use music as a method for self-expression for those with cancer. He has also worked with people with dementia using music as a resource for socialization and memory building.

The second author, the facilitator of the RR sessions, is a Certified Therapeutic Recreation Specialist (CTRS) with a background in music performance and music education. She has worked with diverse populations using music as coping mechanism for trauma, for helping children with Autism Spectrum Disorder (ASD), and in medical-clinical settings for people with cancer.

\section{Restorative rhythms programme}

Robb, Carpenter, and Burns (2011) put forth a recommended set of guidelines for implementing a music-based intervention programme, which included: the intervention itself (structured playing, improvisational playing, listening); consideration of the music selected, who chose it and how it was played (live or recorded); the materials used (i.e. type of instrument); the facilitator of the intervention; the schedule of intervention (how many sessions); and the setting and participants involved. RR was devised by the second author as a series of four 1-hour classes over four weeks, intentionally designed to be welcoming to people with no background in music making. In addition to lifelong training in percussion, she also had completed a Remo HealthRHYTHMS ${ }^{\circledR}$ course to further prepare her for facilitating the programme. Each class of the four course suite included basic guidelines on technique (how to hold the drum, how to hit it, basic patterns); facilitator-led playing (often in accompaniment to well-known songs); improvisational play (often in accompaniment to participant chosen songs); opportunities for participants to talk about the music making experience and any issues or emotions that it might have brought to the surface; and creative opportunities for participants to make small groups and create their own patterns to "tell a story" that they wanted to tell. The second author also played guitar and sang in parts of the programme, as well as played the various drums and offered oneon-one instruction for those who needed it. Remo Comfort Sound Technology ${ }^{\mathrm{TM}}$ hand drums were used for the programme.

\section{Participants}

Interviews were conducted with nine participants who either had cancer at the time of interview or were in remission. All interview participants were female, with an average age of 59. Seven of the participants are white and two are black. Four interviews were conducted with caregivers but were not included in this analysis. Pseudonyms were assigned to protect identity. All participants were told about the research agenda behind RR at the first drumming session, though they were not asked to participate in an interview until the end of the programme. Additionally, the fliers used to promote the programme clearly indicated the research aspect. Participants were chosen using purposive sampling (Patton, 1990) based on their willingness to talk about their experiences with cancer and their participation in RR. We told each group before and after the four-week session about the research component, and upon the end of the fourth week, only 
those that expressed their interest to participate in the interview portion were interviewed. Most participants scheduled a time after their last class.

\section{Interviews}

Semi-structured interviews were conducted with each participant following a pre-established set of questions to understand their historical relationship to music, their diagnosis of cancer and their treatment programme, their participation in RR, and their process of "cognitive rebuilding" post-diagnosis of cancer. Questions included: How important is music to your quality of life (QOL)? How would you have described yourself pre-diagnosis of cancer? How would you describe the feeling of being diagnosed with cancer? What have been the best support mechanisms in your recovery process? And, what motivated you to enrol in the RR programme? Interviews typically lasted about an hour, though several lasted ninety minutes.

\section{Trustworthiness}

Validity and reliability were established for this study through member checks (Crotty, 2010). The first author informally spoke with several of the participants on subsequent interactions at the local art-based cancer support centre after the analysis and writing process began. The purpose of this was to confirm the accuracy of how the data were interpreted. Additionally, an impartial qualitative observer (i.e. one unaffiliated with the study) reviewed the manuscript to provide feedback and seek clarity where applicable. The study was approved by the university's institutional review board (IRB).

\section{Participant observation and "conversation netting"}

The first author undertook this investigation as an observer and the second author was the instructor for all of the RR classes. As an observer, the first author took notes throughout each class session from an obstructed seat in the back of the room to best disguise his presence. Aside from introductions and "goodbyes" he was not directly involved in any aspect of the class facilitation. All notes then became a part of a larger field journal for the project (Tracy, 2013). As the instructor, the second author facilitated every aspect of the classroom and engagement with the participants. She did not participate in conducting interviews.

As mentioned, all classes were audio recorded in a practice dubbed "conversation netting" (Harmon \& Dunlap, 2018). With permission from the participants, the recorder was turned on for the duration of each class period to capture unscripted and serendipitous comments made by those in the class. As there were no structured questions, this created a loose environment where the drummers could speak freely about their love of music, their cancer experience, as well as the benefits of the RR class in the moment. This yielded a significant amount of irrelevant data, but created the possibility that discussions might arise that were extremely valuable to understanding the phenomenon at hand, including the importance of involvement in creative music making as a resource for PTG. Multiple valuable threads did arise through this methodology.

\section{Data analysis and interpretation}


Analysis occurred through a back-and-forth examination of data using both an inductive and deductive process (Crotty, 2010). This iterative process focused on the realities of each participant's life with cancer and the importance of music in their recovery. A primary and secondary coding technique derived from thorough re-readings of the interview transcripts and field notes was used in the analysis. Primary codes were assigned and then grouped into specific categories using focused coding (Tracy, 2013). The data were managed by establishing the content that spoke to the research question, and then prioritizing the data based on the relevance to the study (Saldaña, 2012). These data provided the foundation for understanding how music was used as a coping mechanism in PTG post-diagnosis of cancer. In vivo themes were chosen that resonated the felt impacts of participation in the RR programme (Tracy, 2013), thus providing a structure of transcendence for participants of the study.

\section{Results and discussion}

Cancer is a 9/11 enemy. It's more about cleanup; it's going to strike you [if it's coming for you]. The oncologist said I'd need to carve, burn, or poison. I asked how long I had to think about it, he said one month. I thought about saying my goodbyes, preparing for the end. Chemo is poison for your body. When I went to the infusion room, the first thing the nurse said was, "we're going to insult your body." I went through that and it was such a battle ... Now that I've gone through this seriously traumatic and life-altering experience, I'm living for the future, looking for the positive. Music helps me with the healing. From interview with Blythe (63, breast and ovarian cancer)

\section{Will the circle be unbroken?}

The RR classes were set up in a circle so that everyone could face each other and find some intimacy with one another in the music making process. "Healing circles" have been used for centuries in Native American communities (cf. Regnier, 1994; Vick, Smith, \& Herrera, 1998), and more recently to attend to issues of restorative justice (cf. Pranis, Stuart, \& Wedge, 2003). And while the intent of the RR classes was not implicitly to invoke the concept of "healing circles," the setup did have that beneficial effect. When participants walked into the RR sessions, not only did they find the room organized in a circle with drums at each seat, but there was also music playing on the sound system with an easy, rhythmic beat that was inviting to people to sit down and play, even to novices. Heather (55, breast cancer) said, "I liked how when we walked in and the music was playing and that sort of kicked us off. When the music ended it was kind of like riding a bike when your parents are holding on and then all of a sudden let go!"

For Heather, and others, the layout and ambience of the room created an environment that was comfortable upon first entry, setting a mood that was relaxed and welcoming, encouraging a social atmosphere. As Hart (2009) evidenced, people with cancer often find it difficult to express their inner, conflicting emotions associated with their illness and treatment process. Similarly here, the laidback and social environment of RR increased the likelihood of socialization through music consumption and production and helped to "normalize" the environment even in light of the reason all were in attendance (cf. Laiho, 2004; Potvin, Bradt, \& Kesslick, 2015). As RR was intended as a complement to concurrent medicalized treatments, whether clinical or psychological, the programme provided an outlet for people to attend to the tangential needs of 
their well-being that they did not find in traditional medical/clinical venues (cf. Daykin et al., 2006; Winefield et al., 2003).

At each of the three iterations of RR, the programme relied on contemporary music to help facilitate playful creativity with the drummers. One of the songs the drummers played that was always very popular was "Will the circle be unbroken?" specifically a version by Johnny Cash and June Carter. Terry (51, breast cancer) said, "When you played the song, Will the circle will be unbroken?, I cried because I felt the love in the room. It's a blessing to be around you because I don't have this in my life." For Terry, and others, this song had emotional significance that was enhanced in the supportive atmosphere of the class. McClean et al. (2012) emphasized that music helps to allow the expression of feelings that are difficult to articulate (cf. DeNora, 2000). When each class played along to this song, in accompaniment to the instructor's singing and guitar playing, it led to a cathartic environment that created an air of positivity embraced by all (Weinberg \& Joseph, 2017), thus setting the tone for open and inclusive environment, regardless of ability, and welcoming of all illness experiences and stories.

\section{Confident and positive}

Music is my inner peace ... Music allows people to attend to the serious issues in their lives and helps them find the courage to express what is bothering them. It allows you to relate to people. It opens up that door that lets you release things that you never thought you could release. Music and art can help you make lifelong friends through common experience and shared emotions ...-From interview with Basie (61, two bouts with breast cancer, one with colon cancer)

Though the participants of RR all reported an overall positive experience with their involvement in the programme, many had previous negative experiences with support groups for cancer; the majority did not find most to their liking. While they did express their felt need for social support outside of their closest caregiver networks, friends and family, they considered what they wanted additional supplemental support to look like. Blythe said of her view of cancer support groups:

Support groups to me were a big "no." I wrote something, and [the Hirsch Wellness Network] published it [in their mailer]: "Why would I want to be a part of you? You're everything I don't want to be. You're sick and you can't do things, and you've lost your memory, and you might be dying, and the world is not the way you thought it was going to be, and you're not going to be who you could've been. I didn't want to be a part of you. But I am a part of you. And when I listen to you, I hear a part of me. I know when you listen to me you hear a part of you. And I am thankful for all of you."

Blythe sought out non-traditional support groups that emphasized arts and creativity. She did not want to go to groups that emphasized "first diagnosis stories" because they were "depressing." She was not alone in this sentiment. Buffy said that:

[I] went to a support group through the hospital and did not find it helpful. So many of the people wanted to focus on their illness, not their wellness. I found that depressing. I am not cancer. I have had cancer, cancer has had me. But I don't identify with that. A lot 
of women internalize their emotions or fears, and groups like RR help people address those conflicting emotions and speak to their inner needs.

What drew many of the participants to RR was its fun environment and lack of emphasis on making cancer the central focus. While some activities did ask participants to respond to their specific experiences if they wanted to, it was not the overriding goal to break down each participant's lived experience with cancer. That they were in the group implied the impact of cancer on their lives; it also implied that they were looking for healthy and fun opportunities to transcend its grip on their lives. This does not mean that participants did not introduce the subject of cancer into the group session. In fact, it frequently came up and this was one of the benefits of "conversation netting" to capture the unforced discussion of the relevant topic of cancer in their lives, and the benefit of programmes like RR to help them overcome its reach. Many times these discussions were very matter-of-fact or candid, in large part due to the comfortable and engaging atmosphere set by the class and instructor.

During one session the group was playing along to the public domain song "Take Time in Life" and decided to change its lyrics to meet their collective feeling of fighting cancer. They changed the lyrics to: "As I was drumming by, my sister said to me, she said, find your beat, find your beat. You better take time in life, sister, to find your beat." From here, the group started to improvise and segue into an original song they later titled, "Confident and Positive." Every four beats Blythe would yell, "Positive"; Basie would say, "I am, I am" before Blythe's cry; Gayle (61, lung cancer) was "rapping" throughout, with lines like, "I am confident, strong, delightful, powerful"; and Claire (62, breast cancer) ended the song by shouting, "I don't care what you think - I am going to be positive!" While some support groups unintentionally emphasize the negative aspects of an illness, these participants "mirrored" the positive inside one another as another step in the healing process (cf. Pothoulaki et al., 2012; Ragg et al., 2019), thus allowing for the cathartic release of emotions that some described as "difficult to articulate."

\section{Beat the cancer away!}

There's a song by Rance Allen called, "I will trust in the Lord." And when I was going through chemo, I was like telling the devil "this means war" and I'm not going to give up, I'm not going to lose the fight. That song was very helpful then. Music gave me courage when I was fighting cancer. I drew courage and strength from the music. I just needed the music to channel that inner-strength. - From interview with Nancy (58, breast cancer)

Kleiber et al.'s (2002) four functions for leisure as a coping mechanism are relevant and valuable to the RR programme and its participants. The drummers used leisure to buffer against the impact of cancer through creative music making; they generated optimism by finding shared experiences - and shared catharsis - in the playful environment; and they facilitated the reconstruction of their life story as a vehicle for transformation by connecting to their personal histories with music.

All were able to connect the processing of their unique experience with cancer and their consumption - and now production - of music. Buffy said that, "I don't know how [music] could 
be more important than it was before. Music has always been a thread of normalcy and continuity for me. Music has a fluid structure to it that helps me to redesign my life, to go through infusions, to get well. Music allows me to connect to [my husband], to what's important to me, to my life." Heather concurred, reflecting on her lifelong love of music. She said, "I'll hear a song and feel it speaks to the scenario based on the lyrics; that it sums up what I'm going through perfectly. It really can be like a mantra. I found that certain songs I hadn't thought about in decades resurfaced when I was in treatment and captured the essence of what I was going through." For these participants, not only did they connect to their personal histories with music to establish their growth and continuity, but also to speak to their trials and tribulations associated with cancer diagnoses and the recovery process. In finding a creative outlet like the RR programme, the drummers were able to enact their agency and feel a sense of taking control back from the disease that controlled them (cf. MacMillan et al., 2012; Potvin et al., 2015). Heather proclaimed proudly that, through RR, "We're beating the cancer away!"

\section{Conclusion}

The second author of this study, who led each of the twelve classes (four per series), developed a semi-structured learning experience that was held to four simple "guidelines": (1) listen more than you speak; (2) tune into yourself and others; (3) be in the moment; and (4) leave space for others. While she developed an itinerary for the class to follow at each session, there was a lot of flexibility built in to address personal needs and interests, as well as the comfort level and proficiency of the respective classes; some sessions had more naturally rhythmic drummers than others (Potvin et al., 2015). These simple guidelines complemented Kleiber et al. (2002) four functions of leisure as a coping mechanism for overcoming negative life events: to buffer the impact of negative life events by distraction; to generate optimism; to facilitate reconstruction of one's life story; and to serve as a vehicle for personal transformation. Through the simple and enjoyable act of creative music making, the drummers were able to become stronger by growing in the educational and compassionate environment of the RR classes. As they responded to their personal histories with music, linking those to their illness experiences and the facilitation of their agency through participation (Janke \& Jones, 2016), they found avenues to grow through music (MacMillan et al., 2012; Pothoulaki et al., 2012; Wood, Ivery, Donovan, \& Lambin, 2013). That music for most participants had been of significant importance throughout their lives, and was found to be a valuable resource in their recovery from cancer and adjustment to their "new normal," reinforces the need to focus on lifelong leisure activities, like music consumption/production, as a tool for articulating hard-to-express emotions and coping with life tragedies and traumas like cancer.

At the final class of an iteration of RR, Laura (55, ovarian cancer) recounted a story from the previous week's session. She had been walking alone in the dark to her car after class when all of a sudden she heard Brad (61, caregiver) pound out a little rhythm on his drum to say goodnight to her. In retelling the story she indicated she all of a sudden felt safer in the night, and that maybe things were not as bad as she had thought. She said that, "The drums are here to protect you. You can walk safely in their echo." For Laura, and others, participation in a creative music making group with those who had similar illness experiences allowed for a reframing of one's outlook through the realization that they were not alone in their journey. Traditional support groups, typically held at the cancer centre, were largely not what participants were looking for in 
terms of support. That they were able to participate in a fun and creative environment where the emphasis was on wellness and recovery, instead of the illness and treatment, greatly benefitted their outlook. Therapeutic drumming became an accessible skill they could invite into their lives, and thus a mechanism for release when confusing or negative emotions related to their illness troubled them; they now had the power to drum those feelings away.

\section{Disclosure statement}

No potential conflict of interest was reported by the authors.

\section{References}

Akombo, D. (2013). Effects of community African drumming on generalized anxiety in adolescents. Approaches: Music Therapy \& Music Special Education, 5(1), 25-33.

Arpawong, T. E., Oland, A., Milam, J. E., Ruccione, K., \& Meeske, K. A. (2013). Post-traumatic growth among an ethnically diverse sample of adolescent and young adult cancer survivors. Psycho-Oncology, 22, 2235-2244.

Cross, I. (2001). Music, cognition, culture, and evolution. Annals of the New York Academy of Sciences, 930, 28-42. doi: 10.1111/j.1749-6632.2001.tb05723.x

Crotty, M. (2010). The foundations of social research: Meaning and perspective in the research process. Thousand Oaks, CA: Sage.

Daykin, N., Bunt, L., \& McClean, S. (2006). Music and healing in cancer care: A survey of supportive care providers. The Arts in Psychotherapy, 33, 402-413.

doi: 10.1016/j.aip.2006.07.001

DeNora, T. (1995). The music composition of social reality? Music, action and reflexivity. The Sociological Review, 43(2), 295-315. doi: 10.1111/j.1467-954X.1995.tb00605.x

DeNora, T. (2000). Music in everyday life. Cambridge: Cambridge University Press.

Deraney, J., Davis, M., Evers, H. B., German, K., Hamill, J. C., Karas-Irwin, B. S., ... Shaw, R. E. (2017). Drumming effect on anxiety. Archives of Psychiatric Nursing, 31, 528-529. doi: 10.1016/j.apnu.2017.05.001

Dickerson, D., Robichaud, F., Teruya, C., Nagaran, K., \& Hser, Y.-I. (2012). Utilizing drumming for American Indians/Alaska natives with substance use disorders: A focus group study. The American Journal of Drug and Alcohol Abuse, 38(5), 505-510.

doi: 10.3109/00952990.2012.699565

Docherty, A. (2004). Experience, functions and benefits of a cancer support group. Patient Education and Counseling, 55, 87-93. doi: 10.1016/j.pec.2003.08.002

Fernandez, R. A. (2006). From Afro-Cuban rhythms to Latin jazz. Berkeley: University of California Press.

Glover, T. D., \& Parry, D. C. (2009). A third place in the greater everyday lives of people living with cancer: Functions of Gilda's Club of greater Toronto. Health \& Place, 15, 97-106. doi: 10.1016/j.healthplace.2008.02.007 
Hargreaves, D. J., \& North, A. C. (1999). The functions of music in everyday life: Redefining the social in music psychology. Psychology of Music, 27, 71-83.

doi: $10.1177 / 0305735699271007$

Harmon, J., \& Adams, R. G. (2018). Building a life note-by-note: Music and the life course. World Leisure Journal, 60(2), 140-155. doi: 10.1080/16078055.2018.1444670

Harmon, J., \& Dunlap, R. (2018). Gonzo autoethnography: The story of Monkey. Leisure Sciences, 1-13. doi: 10.1080/01490400.2018.1499057

Hart, J. (2009). Music therapy for children and adults with cancer. Alternative and Complementary Therapies, 15(5), 221-225. doi: 10.1089/act.2009.15510

Janke, M. C., \& Jones, J. J. (2016). Using leisure to find a way forward after loss: A lifespan perspective. In D. A. Kleiber, \& F. A. McGuire (Eds.), Leisure and human development (pp. 293-317). Urbana, IL: Sagamore.

Joon, P. J.-C. (2001). "She really becomes Japanese now!": Taiko drumming and Asian American identifications. American Music, 19(4), 417-438. doi: 10.2307/3052419

Karnilowicz, W. (2011). Identity and psychological ownership in chronic illness and disease state. European Journal of Cancer Care, 20, 276-282. doi: 10.1111/j.1365-2354.2010.01220.x

Kenyon, T. (2007). Effects of music therapy on surgical and cancer patients. Breast Care, 2, 217-220. doi: 10.1159/000105380

Kleiber, D. A., Hutchinson, S. L., \& Williams, R. (2002). Leisure as a resource in coping with negative life events" self-protection, self-restoration, and personal transformation. Leisure Sciences, 24(2), 219-235. doi: 10.1080/01490400252900167

Kruse, J. (2003). Music therapy in United States cancer settings: Recent trends in practice. Music Therapy Perspectives, 21, 89-98. doi: 10.1093/mtp/21.2.89

Laiho, S. (2004). The psychological functions of music in adolescence. Nordic Journal of Music Therapy, 13(1), 47-63. doi: 10.1080/08098130409478097

MacMillan, T., Maschi, T., \& Tseng, Y.-F. (2012). Measuring perceived well-being after recreational drumming: An exploratory factor analysis. Families in Society: The Journal of Contemporary Social Services, 93(1), 74-79. doi: 10.1606/1044-3894.4180

Maschi, T., MacMillan, T., \& Viola, D. (2012). Group drumming and well-being: A promising self-care strategy for social workers. Arts \& Health, 5(2), 1-10.

McClean, S., Bunt, L., \& Daykin, N. (2012). The healing and spiritual properties of music therapy at a cancer care center. The Journal of Alternative and Complementary

Medicine, 18(4), 402-407. doi: 10.1089/acm.2010.0715

Merriam, A. P. (1964). The anthropology of music. Chicago, IL: Northwestern University Press.

Nzewi, M., Anyahuru, I., \& Ohiaraumunna, T. (2001). Beyond song texts: The lingual fundamentals of African drum music. Research in African Literatures, 32(2), 90-104. 
Öster, I., Aström, S., Lindh, J., \& Magnusson, E. (2009). Women with breast cancer and gendered limits and boundaries: Art therapy as a 'safe space' for enhancing alternative subject positions. The Arts in Psychotherapy, 36, 29-38. doi: 10.1016/j.aip.2008.10.001

Parry, D. C. (2007). "There is life after breast cancer": nine vignettes exploring dragon boat racing for breast cancer survivors. Leisure Sciences, 29, 53-69.

doi: 10.1080/01490400600983420

Patton, M. (1990). Qualitative evaluation and research methods. Newbury Park, CA: Sage.

Petterson, M., \& Loy, D. P. (2008). Comparing the effectiveness of animal interaction, digital music relaxation, and humor on the galvanic skin response of individuals with Alzheimer's disease: Implications for recreational therapy. Annual in Therapeutic Recreation, 16, 139-152.

Plastow, N. A., Joubert, L., Chotoo, Y., Nowers, A., Greeff, M., Strydom, T., ... van Niekerk, E. (2018). The immediate effect of African drumming on the mental well-being of adults with mood disorders: An uncontrolled pretest-posttest pilot study. The American Journal of Occupational Therapy, 72(5), 1-6. doi: 10.5014/ajot.2018.021055

Pothoulaki, M., MacDonald, R., \& Flowers, P. (2005). Music interventions in oncology settings: A systematic literature review. British Journal of Music Therapy, 19(2), 75-83. doi: $10.1177 / 135945750501900206$

Pothoulaki, M., MacDonald, R., \& Flowers, P. (2012). An interpretive phenomenological analysis of an improvisational music therapy program for cancer patients. Journal of Music Therapy, 49(1), 45-67. doi: 10.1093/jmt/49.1.45

Potvin, N., Bradt, J., \& Kesslick, A. (2015). Expanding perspective on music therapy for symptom management in cancer care. Journal of Music Therapy, 52(1), 135-167.

doi: $10.1093 / \mathrm{jmt} /$ thu056

Pranis, K., Stuart, B., \& Wedge, M. (2003). Peacemaking circles: From conflict to community. St. Paul, MN: Living Justice Press.

Ragg, D. M., Soulliere, J., \& Turner, M. (2019). Drumming and mindfulness integrations into an evidence-based group intervention. Social Work with Groups, 42(1), $29-42$.

doi: 10.1080/01609513.2017.1402401

Regnier, R. (1994). The sacred circle: A process pedagogy of healing. Interchange, 25(2), 129144. doi: 10.1007/BF01534540

Rentfrow, P. J., McDonald, J. A., \& Oldmeadow, J. A. (2009). You are what you listen to: Young people's stereotypes about music fans. Group Processes \& Intergroup Relations, 12(3), 329-344. doi: 10.1177/1368430209102845

Robb, S. L., Carpenter, J. S., \& Burns, D. S. (2011). Reporting guidelines for music-based interventions. Journal of Health Psychology, 16(2), 342-352. doi: 10.1177/1359105310374781

Ruud, E. (1997a). Music and identity. Nordic Journal of Music Therapy, 6(1), 3-13.

Ruud, E. (1997b). Music and the quality of life. Nordic Journal of Music Therapy, 6(2), 86-97. 
Rykov, M. H. (2008). Experiencing music therapy cancer support. Journal of Health Psychology, 13(2), 190-200. doi: 10.1177/1359105307086708

Saarikallio, S., \& Erkkilä, J. (2007). The role of music in adolescents' mood regulation. Psychology of Music, 35(1), 88-109. doi: 10.1177/0305735607068889

Saldaña, J. (2012). The coding manual for qualitative researchers. Thousand Oaks, CA: Sage.

Schäfer, T., \& Sedlmeier, P. (2009). From the functions of music to music preference. Psychology of Music, 37(3), 279-300. doi: 10.1177/0305735608097247

Schlaug, G., Norton, A., Overy, K., \& Winner, E. (2005). Effects of music training on the child's brain and cognitive development. Annals of the New York Academy of Sciences, 1060, 219-230. doi: 10.1196/annals.1360.015

Scrignaro, M., Barni, S., \& Magrin, M. E. (2011). The combined contribution of social support and coping strategies in predicting post-traumatic growth: A longitudinal study of cancer patients. Psycho-Oncology, 20, 823-831. doi: 10.1002/pon.1782

Stephens, R. W. (2014). Performing belief: Representing experience in Ocha-Ifa drumming. International Journal of Religion \& Spirituality in Society, 3(3), 1-11. doi: 10.18848/2154-8633/CGP/v03i03/51057

Tedeschi, R. G., \& Calhoun, L. G. (2004). Posttraumatic growth: Conceptual foundations and empirical evidence. Psychological Inquiry, 15(1), 1-18. doi: 10.1207/s15327965pli1501_01

Tracy, S. (2013). Qualitative research methods: Collecting evidence, crafting analysis, communicating impact. Hoboken, NJ: Wiley-Blackwell.

Vick, R. D., Smith, L. M., \& Herrera, C. I. R. (1998). The healing circle: An alternative path to alcoholism recovery. Counseling and Values, 42, 133-141. doi: 10.1002/j.2161007X.1998.tb00418.x

Weinberg, M. K., \& Joseph, D. (2017). If you're happy and you know it: Music engagement and subjective wellbeing. Psychology of Music, 45(2), 257-267. doi: 10.1177/0305735616659552

Winefield, H. R., Coventry, B. J., Lewis, M., \& Harvey, E. J. (2003). Attitudes of patients with breast cancer toward support groups. Journal of Psychosocial Oncology, 21(2), 39-54.

doi: $10.1300 / J 077 \mathrm{v} 21 \mathrm{n} 02 \_03$

Wood, L., Ivery, P., Donovan, R., \& Lambin, E. (2013). "To the beat of a different drum": Improving the social and mental wellbeing of at-risk young people through drumming. Journal of Public Mental Health, 12(2), 70-79. doi: 10.1108/JPMH-09-2012-0002

Yildirim, Y., \& Kocabiyik, S. (2010). The relationship between social support and loneliness in Turkish patients with cancer. Journal of Clinical Nursing, 19, 832-839. doi: 10.1111/j.13652702.2009.03066.x 